
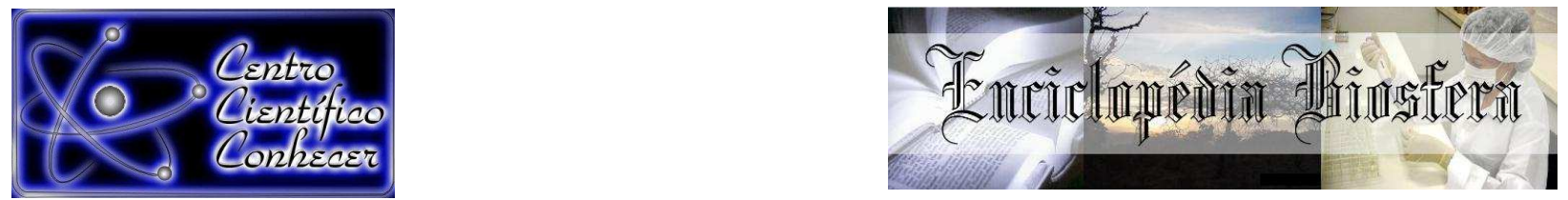

\title{
OCORRÊNCIA CONCOMITANTE DE METÁSTASE DE CARCINOMA DE CÉLULAS ESCAMOSAS PARA PULMÃO E MIELOENCEFALITE PROTOZOÁRIA EQUINA: RELATO DE CASO
}

Alessandra Castro Rodrigues ${ }^{1}$, Érica Almeida Viscone' ${ }^{1}$, Lígia Assunção Oliveira1, Kamila Pinheiro Paim², Alessandra Aparecida Medeiros-Ronchi ${ }^{3}$

1-Residente em Patologia Animal, Universidade Federal de Uberlândia, Uberlândia MG. E-mail: alessandracastroveterinaria@gmail.com

2-Residente em Clínica e Cirurgia de Grandes Animais, Universidade Federal de Uberlândia, Uberlândia - MG

3-Professora doutora em Patologia Animal, Universidade Federal de Uberlândia, Uberlândia-MG.

Recebido em: 02/10/2017 - Aprovado em: 21/11/2017 - Publicado em: 05/12/2017 DOI: 10.18677/EnciBio 2017B43

\begin{abstract}
RESUMO
A mieloencefalite protozoária equina é uma doença infectocontagiosa causada principalmente pelo protozoário Sarcocystis neurona, acometendo o sistema nervoso central dos equinos. O diagnóstico desta patologia é clínico, devido à dificuldade de identificação dos cistos de protozoários na avaliação histológica, sendo recomendada a técnica de imunohistoquímica para esta finalidade. O carcinoma de células escamosas (CCE) é uma neoplasia maligna comum na espécie equina, com origem nas células epiteliais da epiderme que sofrem diferenciação para queratinócitos. Possui caráter infiltrativo local e ocorrência incomum de metástases. Objetivou-se relatar a ocorrência de encefalite protozoária equina juntamente com caso incomum de metástase de carcinoma de células escamosas em pulmão de equino. $O$ animal de vinte anos de idade, sem raça definida, foi encaminhado ao setor de patologia do Hospital Veterinário da Universidade Federal de Uberlândia para realização de exame necroscópico e microscópico. O animal apresentava massa localizada no prepúcio e foi submetido à exérese cirúrgica da massa. Após o procedimento cirúrgico o equino apresentou sintomatologia nervosa e foi submetido à eutanásia. No exame necroscópico coletou-se fragmento de encéfalo e pulmão, que apresentava nódulo circunscrito. Histologicamente diagnosticou-se metástase de CCE no pulmão e, apesar de difícil identificação na avaliação histológica, cistos de protozoário no encéfalo compatíveis com Sarcocystis ssp.
\end{abstract}

PALAVRAS-CHAVE: carcinoma epidermoide, cavalo, Sarcocystis.

\section{CONCURRENT OCCURRENCE OF LUNG METASTASIS OF SQUAMOUS CELL CARCINOMA AND EQUINE PROTOZAN MYELOENCEPHALITIS: CASE REPORT}

\footnotetext{
ABSTRACT

Equine protozoal myeloencephalitis is an infectious-contagious disease caused mainly by the protozoan Sarcocystis neuron, affecting the central nervous system of horses. The diagnosis of this pathology is clinical, due to the difficulty in identifying 
the cysts of protozoa in the histological evaluation, thus the immunohistochemical technique is recommended for this purpose. Squamous cell carcinoma (SCC) is a malignant neoplasm common to the equine species, originating from the epithelial cells of the epidermis that undergo differentiation for keratinocytes. It has local infiltrative characteristic and unusual occurrence of metastases. The goal of this study was to report the occurrence of equine protozoal encephalitis altogether with an unusual case of squamous cell carcinoma metastasis in an equine lung. The twenty-year-old, mixed-breed animal was referred to the pathology department of the Veterinary Hospital of the Federal University of Uberlândia for necroscopic and microscopic examination. The animal presented a mass located in the foreskin and underwent surgical excision of the mass. After the surgical procedure the horse presented nervous symptoms and was submitted to euthanasia. In the necroscopic exam, a fragment of the brain and lung with a circumscribed nodule were collected. Histologically, SCC metastasis was diagnosed in the lung and, although with difficulty to identify in the histological evaluation, protozoal cysts in the brain compatible with Sarcocystis ssp.

KEYWORDS: squamous cell carcinoma, horse, Sarcocystis.

\section{INTRODUÇÃO}

O carcinoma de células escamosas (CCE) é uma neoplasia maligna com origem nas células epiteliais da epiderme, que sofrem diferenciação para queratinócitos (GOLDSCHMIDT; GOLDSCHMIDT, 2017). É frequentemente diagnosticado em todos os animais domésticos (GOLDSCHMIDT; GOLDSCHMIDT, 2017), e em equinos é relatada como um dos tumores cutâneos de maior ocorrência nestes animais (CARVALHO et al., 2014; SILVA et al., 2015; SPRENGER et al., 2014), juntamente com o sarcoide equino (RAMOS et al., 2007).

Em equinos, esta neoplasia tem predileção pelas junções cutâneas, como pálpebras, vulva e períneo e esta associada à exposição exagerada aos raios ultravioletas, animais com falta de pigmentação na epiderme e locais na pele que possuem uma menor quantidade de pelos (GOLDSCHMIDT; GOLDSCHMIDT, 2017).

CCE são comumentemente observados em região de prepúcio nos equinos, sendo também frequentes nesta localização o fibrossarcoma, hemangioma, mastocitoma, melanoma, sarcóide e papiloma (THRELLFALL; IMMEGART, 2000). Esta neoplasia tem caráter infiltrativo e de crescimento lento, com ocorrência de metástase para linfonodos regionais e raramente para órgãos centrais como os pulmões (GOLDSCHMIDT; GOLDSCHMIDT, 2017; KRAEGEL; MADEWELL, 2004).

A mieloencefalite protozoária equina é uma doença infectocontagiosa causada principalmente pelo protozoário Sarcocystis neurona, mas também pode ser ocasionada pelo Neospora caninum e Neospora hughesi acometendo o sistema nervoso central dos equinos. (ECCO et al., 2017; LINS et al., 2012).

Nesta espécie este parasita é considerado acidental, sendo o hospedeiro intermediário os pássaros, e o hospedeiro definitivo o gambá (Didelphis albiventris), que excreta os esporocistos pelas fezes, contaminando a água e os alimentos (ECCO et al., 2017).

Os sinais clínicos são inespecíficos e dependem de onde o protozoário se localiza no sistema nervoso central, podendo ocorrer tanto na substância branca como na cinzenta, e na maioria das vezes as lesões são assimétricas. Além disso, por ocorrer mais frequentemente na medula do que no encéfalo, nota-se 
clinicamente dificuldade de locomoção e comprometimento de membros (FARIAS, 2007).

O diagnóstico é baseado nos sinais clínicos e no diagnóstico terapêutico. No Brasil, uma grande quantidade de casos são negligenciados pela falta do exame necroscópico e histopatológico, impossibilitando o diagnóstico definitivo (FARIAS, 2007).

Objetivou-se relatar a ocorrência rara do diagnóstico de encefalite protozoária equina pelo exame histopatológico, sem a utilização da técnica de imunohistoquímica, e a presença incomum de metástase de carcinoma de células escamosas para o pulmão do mesmo animal.

\section{RELATO DE CASO}

Um equino, 20 anos de idade, sem raça definida, foi encaminhado ao Hospital Veterinário da Universidade Federal de Uberlândia com queixa de lesão no prepúcio há aproximadamente sete meses. $\mathrm{Na}$ avaliação clínica do animal identificou-se massa localizada no prepúcio, medindo aproximadamente 25,0 centímetros de diâmetro, ulcerada, de superfície irregular, coloração avermelhada e consistência friável (Figura 1). Coletou-se amostra para biópsia incisional que foi acondicionada em formol $10 \%$ tamponado.

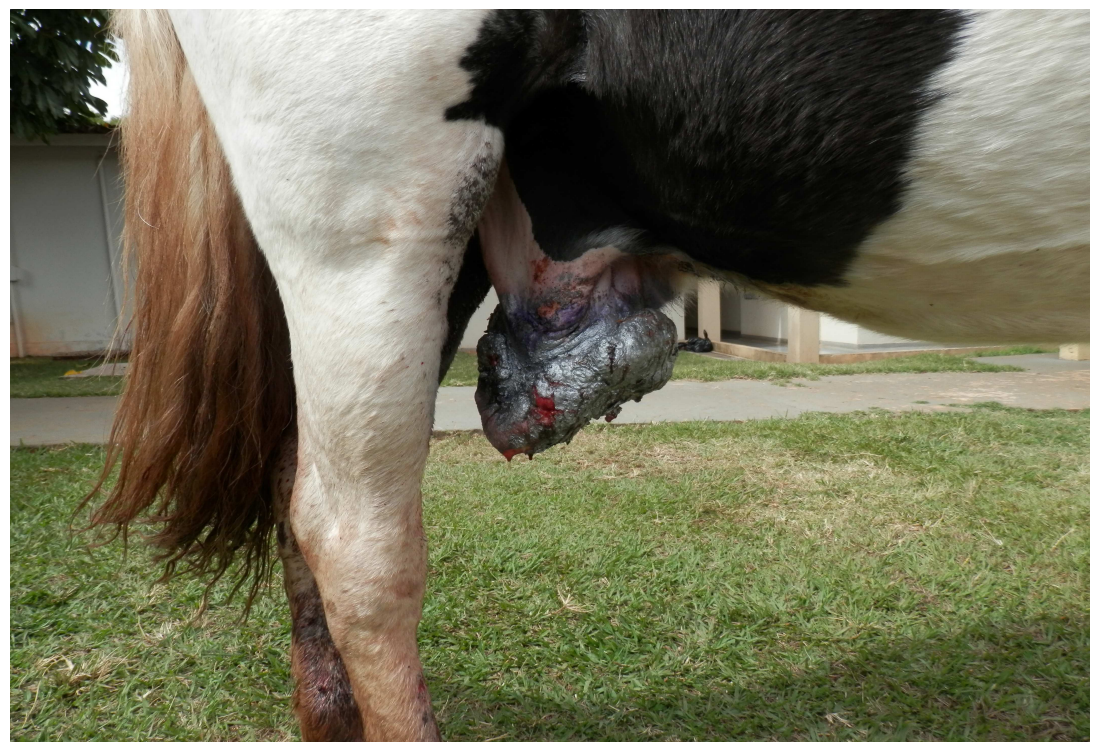

FIGURA 1. Carcinoma de células escamosas no prepúcio de equino, SRD, 20 anos. Massa ulcerada, de superfície irregular, coloração avermelhada e consistência friável. Fonte: Arquivo pessoal.

Foram realizados como exames complementares hemograma e bioquímica sérica (determinação dos níveis de uréia e creatinina séricas), sendo detectada anemia, discreta leucocitose e linfopenia. Recomendou-se exérese cirúrgica como tratamento para a lesão no prepúcio, juntamente com penectomia e uretrostomia. Após a exérese cirúrgica foi instituído como tratamento penicilina benzatina (40.000Ul/kg, cinco aplicações em 48 horas) e hidrocortisona (4mg/kg, IV, BID) para controle da infecção e dor.

Após cinco dias do procedimento cirúrgico, o animal começou a apresentar sintomas neurológicos como dificuldade na apreensão dos alimentos, ataxia de 
membros, desvio do lábio para a esquerda, ptose palpebral esquerda e diminuição do tônus da cauda. Foi então realizado o exame clínico neurológico que indicou déficits facilmente observados durante a locomoção em linha reta e exacerbados durante a realização de manobras especiais. No sexto dia, surgiram outros sinais neurológicos como andar em círculos, reflexo de ameaça diminuído e apatia.

Após sete dias do aparecimento dos sintomas neurológicos, devido ao agravamento do quadro clínico do animal e ao prognóstico desfavorável, optou-se pela eutanásia. $O$ mesmo foi encaminhado para o setor de Patologia Animal para a realização do exame necroscópico, com registro fotográfico das alterações macroscópicas e coleta de fragmentos para avaliação por microscopia.

\section{RESULTADOS E DISCUSSÃO:}

No exame necroscópico observou-se presença de massa localizada no pulmão direito medindo aproximadamente $3,0 \mathrm{~cm}$ de diâmetro, de consistência firme e formato arredondado (Figura 2). Macroscopicamente esta neoplasia pode ser descrita de aspecto papilar a couve-flor, ulcerada, o que pode acarretar infecções secundárias e sangrando muito quando manipulada, ou somente como ulceras que possuem crostas em sua superfície (CONCEIÇÃO; LOURES, 2016). O diagnóstico definitivo é feito microscopicamente por citologia e/ou histologia (TYLER et al., 2009; GOLDSCHMIDT; GOLDSCHMIDT, 2017).

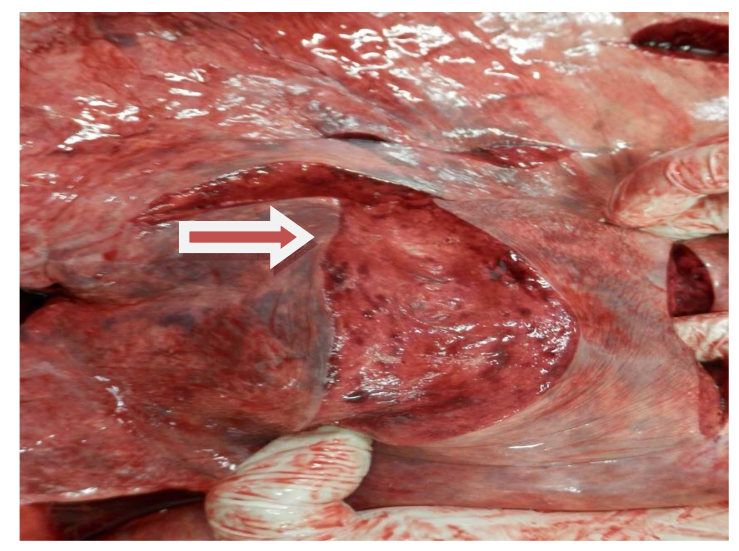

FIGURA 2. Equino, SRD, 20 anos. Pulmão com nódulo medindo aproximadamente $3 \mathrm{~cm}$, brancacento, arredondado. Fonte: Arquivo pessoal.

Não foram observadas lesões macroscópicas conspícuas no sistema nervoso central. Fragmentos de cérebro e medula espinhal, além da massa prepucial, foram coletados para análise microscópica, acondicionadas em formol 10\% tamponado. Confeccionou-se lâminas histológicas de rotina coradas em hematoxilina e eosina.

$\mathrm{Na}$ análise microscópica do fragmento pulmonar observou-se proliferação de células epiteliais bem diferenciadas, de distribuição multifocal. Havia áreas com substancia eosinofílica homogênea, organizada concentricamente e circundada pelas células epiteliais (pérolas de queratina). Células neoplásicas apresentavam formato poligonal, citoplasma em quantidade moderada, de coloração eosinofílica, núcleo de formato redondo, localizado centralmente, coloração basofílica, cromatina frouxa e nucléolo evidente. Presença de moderada anisocitose e anisocariose, com 
moderado pleomorfismo celular, raras figuras de mitose por campo de grande aumento (Figura 3).

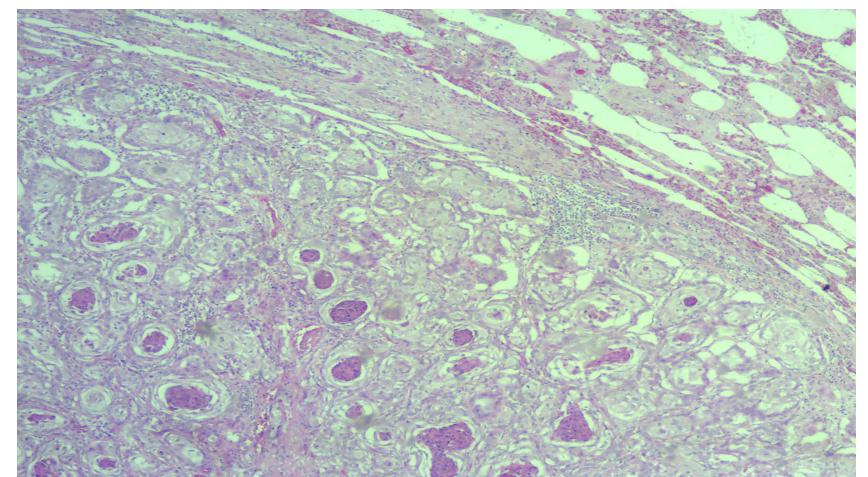

FIGURA 3. Equino, SRD, 20 anos. Fotomicrografia de metástase de carcinoma de células escamosas no pulmão. Aumento de 10X. Fonte: Arquivo pessoal.

Estas características histológicas são compatíveis com CCE. Histologicamente, no CCE as células epiteliais se dispõem em cordões e ilhas ligadas a superfície epidermal, na maioria dos casos e nas neoplasias bem diferenciadas formam pérolas de queratina no centro das células neoplásicas. Apresentam anaplasia, pleomorfismo acentuado, células multinucleadas, nucléolos múltiplos e proeminentes (CONCEIÇÃO; LOURES, 2016).

$\mathrm{Na}$ análise citológica a morfologia das células escamosas depende do grau de diferenciação da neoplasia, sendo esta de difícil diagnóstico quando pouco diferenciada. Em tumores pouco diferenciados notam-se células grande com citoplasma abundante, anisocitose, aumento do número e formatos nucleares, aumento do basofilia citoplasmática, variação na relação núcleo-citoplasma, vacuolização perinuclear (TYLER et al., 2009).

Goldschmidt e Goldschmidt (2017) relataram que o CCE tem apenas caráter infiltrativo no local e pode realizar metástase para linfonodos regionais. No presente relato houve metástase para o pulmão de ocorrência infrequente.

Há escassez de relatos de metástase de CCE para pulmão. Casos relatados por Rosolem et al. (2012) e Silva et al. (2015) também demonstraram a ocorrência de metástase de células escamosas para o pulmão, sendo os dois focos primários das neoplasias os órgãos genitais femininos e masculinos respectivamente, como no presente caso. A associação entre CCE em órgãos genitais e metástase pulmonar como relatados nestes casos sugere que o CCE genital possa possuir características metastáticas.

Microscopicamente no sistema nervoso central, notou-se grande quantidade de células inflamatórias perivasculares, predominantemente eosinófilos. Além disso, havia a presença de cistos de protozoários na substância branca, compatíveis com Sarcocystis ssp. (Figura 4). 


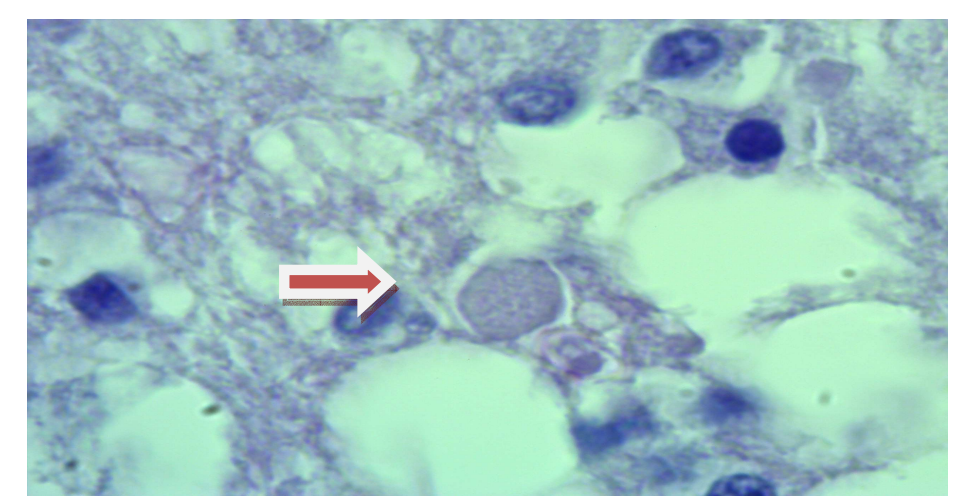

FIGURA 4. Equino, SRD, 20 anos. Fotomicrografia de cérebro com presença de cistos de protozoários na substância branca. Aumento de 100X. Fonte: Arquivo pessoal.

De acordo com Ecco et al. (2017), no caso de mieloencefalite protozoária equina, o infiltrado inflamatório presente no encéfalo é de eosinófilos. Estes autores relatam a dificuldade no diagnóstico histológico e que apenas um terço dos casos é diagnosticado utilizando a técnica de imunohistoquímica. Ressalta-se o sucesso na identificação dos cistos protozoários no presente relato, sem a utilização da técnica de imunohistoquímica. O diagnóstico histológico pode ser otimizado com a realização de secções seriadas da medula e encéfalo, principalmente quando não há lesões macroscópicas, como ocorreu neste caso.

No exame necroscópico notam-se áreas amolecidas no sistema nervoso central e no exame histopatológico observam-se no mesmo, áreas com malácia e infiltrado inflamatório eosinofílico e linfocítico. Em apenas um terço dos casos são encontrados as formas dos parasitas, a maioria delas pela técnica de imunohistoquímica, sejam elas no citoplasma de neurônios e macrófagos ou livres. (ECCO et al., 2017).

Os animais afetados possuem de dois a 24 anos, sendo mais comum a infecção entre um a seis anos. Não há preferência sazonal, por sexo ou localização geográfica. Porém, animais imunossuprimidos possuem uma predileção de desenvolver a doença (FARIA 2007; ECCO et al., 2017).

Antes da realização do procedimento cirúrgico o animal não apresentava sinais neurológicos. Porém, a medicação pós-cirúrgica com corticoesteróides resultou em déficit no sistema nervoso central corroborando com Ecco et al. (2017) que afirmam que a imunossupressão relacionada ao uso desses medicamentos pode ser determinante para a manifestação da doença.

\section{CONCLUSÃO}

A confirmação de casos de encefalomielite protozoária equina é de grande importância epidemiológica, pois chama a atenção para a necessidade de controle dos hospedeiros definitivos e intermediários no sentido de se evitar novos casos da doença. A encefalomielite protozoária deve ser considerada sempre que houver equinos com sintomatologia neurológica. Nos casos de carcinoma de células escamosas em equinos, principalmente em órgãos genitais, considerar sítios de metástase distantes do foco primário, como no pulmão. 


\section{REFERÊNCIAS:}

CARVALHO, L. F. K.; DANTAS, A. F. M.; RIET-CORREA, F.; DE ANDRADE, R. L. F. S.; NETO, P.I.N.; NETO, E. G. M.; SIMÕES, S. V. D.; AZEVEDO, S. S. Estudo retrospectivo das neoplasias em ruminantes e equídeos no semiárido do Nordeste Brasileiro. Pesquisa veterinária Brasileira. v. 34, n. 3, p. 211-216, 2014. Disponível em: $\quad$ http://www.scielo.br/scielo.php?script=sci_arttext\&pid=S0100736X2014000300003\&lng=pt\&tlng=pt DOI: http://dx.doi.org/10.1590/S0100736X2014000300003

CONCEIÇÃO, L. G.; LOURES, F. H. Sistema Tegumentar. In: Santos, R. L.; Alessi, A. C. Patologia Veterinária. $2^{\mathrm{a}}$ ed. Rio de Janeiro: Guanabara/Koogan, 2016.

ECCO, R.; VIOTT, A. M.; GRAÇA, D. L.; ALESSI, A. C. Sistema Nervoso. In: Santos, R. L.; Alessi, A. C. Patologia Veterinária. $2^{\mathrm{a}}$ ed. Rio de Janeiro: Guanabara Koogan, 2017.

FARIAS, A. N. Doenças parasitárias. In: Riet-correa, F.; Schild, A. L.; Méndez, M. C.; Lemos, R. A. A.; Borges, J. R. J. Doenças de ruminantes e eqüinos. $3^{\underline{a}}$ ed. Santa Maria: Pallotti, 2007.

GOLDSCHMIDT, M. H., \& GOLDSCHMIDT, K.H. Epithelial and Melanocytic Tumors of the Skin. In Meuten, D. J., Tumors in Domestic Animals. $5^{\underline{a}}$ ed. lowa: John Wiley \& Sons; 2017.

LINS, A. L.; FEIJÓ, S. L.; NOGUEIRA, W.E.C. Mieloencefalite protozoária equina nas regiões da Campanha e do sul do Rio Grande do Sul no período de 1998-2006. Revista de Ciências Agroveterinárias. v.11 n.3, p. 248-250, 2012. Disponível em: http://revistas.bvs-vet.org.br/rca/article/view/34295/38353. DOI:

KRAEGEL, S. A.; MADEWELL, B. R. Tumores da Pele. In: Ettinger, S. J.; Feldmann, E. C. Tratado de Medicina Interna Veterinária. 5.ed. Rio de Janeiro: Guanabara/Koogan, 2004.

RAMOS, A. T.; NORTE, T. M.; ELIAS, F.; FERNANDES C. G. Carcinoma de células escamosas em bovinos, ovinos e eqüinos: estudo de 50 casos no sul do Rio Grande do Sul. Brazilian Journal of Veterinary Research and Animal Science. v. 44, p. 513, 2007. Disponível em: https://www.revistas.usp.br/bjvras/article/view/26583 DOI: http://dx.doi.org/10.11606/issn.1678-4456.bjvras.2007.26583

ROSOLEM, M. C.; ROMERO, D. C.; PACHECO, A. D.; SCHWEIGERT, A.; ROZZA, D. B. Carcinoma de células escamosas em assoalho vaginal de um bovino nelore associado à metástase em pulmão -Relato de caso. Revista científica eletrônica de medicina veterinária. v. $9, \mathrm{n} .18, \quad$ p. 1-7, 2012. Disponível em: http://hdl.handle.net/11449/133100

SILVA, S. C. G.; ALVES A. D. F.; RÖNNAU, M.; TORRES M. B. A. M. Carcinoma de células escamosas em equino com metástase pulmonar: Relato de caso. Revista Brasileira de Higiene e Sanidade Animal. v. 9, n. 3, p. 543-552, 2015. Disponível 
em: http://www.higieneanimal.ufc.br/seer/index.php/higieneanimal/article/view/285 DOI: http://dx.doi.org/10.5935/1981-2965.20150050

SPRENGER, L. K.; GABARDO, L. B.; RISOLIA L. W.; MOLENTO, M. B.; DA SILVA A. W. C.; DE SOUSA, R. S. Frequência de neoplasias cutâneas em equinos: estudo retrospectivo do laboratório de patologia veterinária da universidade federal do Paraná. Archives of Veterinary Science. v.19, n.3, p.81-86, 2014. Disponível em: https://www.researchgate.net/publication/287594156_FREQUENCIA_DE_NEOP LASIAS_CUTANEAS_EM_EQUINOS_ESTUDO_RETROSPECTIVO_DO_LABO RATORIO_DE_PATOLOGIA_VETERINARIA_DA_UNIVERSIDADE_FEDERAL_ DO_PARANA DOI: 10.5380/avs.v19i3.35774

THRELLFALL, W.R.; IMMEGART, H. M. Neoplasias do trato reprodutivo do garanhão. In: Reed, S.M.; Bayly, W.M., Medicina Interna Equina. 1를 Ed. Rio de Janeiro: Guanabara Koogan , 2000.

TYLER, R.D.; COWELL R.L.; MEINKOTH, J. H. Lesões Cutâneas e Subcutâneas. In Cowell, R. L.; Tyler, R. D.; Meinkoth, J. H.; DeNicola, D. B. Diagnóstico Citológico e Hematologia de Cães e Gatos. 3ª ed. São Paulo: Editora MedVet, 2009. 